\title{
Evaluation of differences in health-related quality of life in patients receiving conventional versus newer anti-epileptic drugs
}

\author{
Kavisha S. Goswami ${ }^{1}$, Devang A. Rana ${ }^{2 *}$, Shalin Shah $^{3}$, Supriya D. Malhotra ${ }^{1}$
}

\author{
${ }^{1}$ Smt. N.H.L. Municipal Medical College, Ahmedabad, Gujarat, India \\ ${ }^{2}$ Department of Pharmacology, ${ }^{3}$ Department of Neurology, Smt. N.H.L. Municipal Medical College, \\ Ahmedabad, Gujarat, India
}

Received: 17 September 2019

Revised: 28 December 2019

Accepted: 02 January 2020

*Correspondence:

Dr. Devang A. Rana,

Email: devangandu@gmail.com

Copyright: (c) the author(s), publisher and licensee Medip Academy. This is an open-access article distributed under the terms of the Creative Commons Attribution Non-Commercial License, which permits unrestricted non-commercial use, distribution, and reproduction in any medium, provided the original work is properly cited.

\begin{abstract}
Background: Epilepsy is associated with stigma and bad health-related quality of life (HR-QOL) due to this, and side effects of the drug therapy. Newer anti-epileptics are claimed to be better than the conventional. We evaluated this based on comparison of HR-QOL in patients taking the respective therapy.

Methods: An observational, cross-sectional, single point study involved 127 consenting patients from Neurology OPD at V.S. General Hospital. Quality of life in epilepsy-10 (QOLIE-10) questionnaire was used to measure HRQOL in patients. SPSS software and Graphpad prism were used to analyze the variables.

Results: Patients of 20-30 age group were commonly affected (37.80\%) with a male predominance $(56.69 \%) .41 .73 \%$ were unemployed. The difference in HR-QOL between patients and controls in all three domains (epilepsy effects, mental effects, role function domains) of QOLIE-10 was significant $(\mathrm{p}=0.0002)$, indicating better HR-QOL in controls. The worst HR-QOL scores were found in Epilepsy effects domain. Metabolic adverse effects (38.58\%) were the common ADRs. Sodium valproate was the most effective in controlling seizures (last seizure episode: 15 months). HR-QOL correlation between patients receiving monotherapy and polytherapy was significant $(\mathrm{p}=0.026)$ with monotherapy rendering a better HR-QOL. Comparison of HR-QOL between patients taking the conventional and the newer drugs was not significant $(\mathrm{p}=0.1768)$.

Conclusions: Our study nullifies the claims that newer drugs are better than the conventional since no such benefit was seen in HR-QOL as well as ADRs. Our findings ruled out the belief that cases of epilepsy are better controlled with polytherapy.
\end{abstract}

Keywords: Drug use pattern, Epilepsy, Quality of life, HR-QOL, Prescription pattern

\section{INTRODUCTION}

Epilepsy is a central nervous system disorder due to abnormal brain activity, causing seizures or periods of unusual behaviour, sensations, and sometimes loss of awareness. Out of 70 million cases of epilepsy worldwide, India lodges 12 million cases. ${ }^{1}$ There are over 20 anti-epileptic drugs (AEDs) and 2 implantable antiepileptic devices available commercially in the United
States. ${ }^{2}$ This list excludes extended release formulations, vagus nerve stimulation technology, and dietary modifications. . $^{3,4}$

The conventional AEDs include phenytoin, carbamazepine, valproic acid, ethosuximide, and newer include zonisamide, lamotrigine, levetiracetam, lacosamide. None of the newer AEDs have been found better than the conventional. However, the "2004 
American Academy of Neurology report" suggested that newer AEDs have same efficacy but better tolerability. ${ }^{5}$

Epilepsy being a social stigma, patients face psychosocial problems. ${ }^{6}$ Increasing awareness about it has led to the need to measure health-related quality of life (HR-QOL) with appropriate AED use and their adverse effects. Demographic characters, seizure frequency, and extended disease window lead to poor HR-QOL. ${ }^{7}$ There are lesser studies examining the impact of AED pharmacotherapy on HR-QOL ${ }^{8}$. Hence, this study will inform us regarding the type of AEDs prescribed along with baseline data on HR-QOL.

The study objectives included analysis of prescription pattern in patients of epilepsy and HR-QOL using disease-specific quality of life in epilepsy inventory (QOLIE)-10 questionnaire and its comparison between patients receiving conventional and new AEDs.

\section{METHODS}

The study began after the written permission of Institutional Ethics Committee. The study was an observational, cross-sectional, single point study, carried out in the outpatient department of neurology of V.S. General Hospital from February 2018 to September 2018, and designed to evaluate patterns of AED use and to examine the impact of factors namely demographic, clinical, and pharmacotherapy characteristics, affecting HR-QOL. Treatment data included the generic names, daily dose, duration, and adverse reaction profile in patients receiving AEDs.

Patients who had been receiving AEDs for at least a month were included in the study. Prescriptions were analyzed for WHO core indicators consisting of mean number of drugs and AEDs prescribed per encounter, mean cost per prescription for AEDs, Percentage of drugs prescribed by generic name and Percentage of drugs prescribed from hospital formulary

Study Population included patients of adult group and either sex with epilepsy and prescribed with an AED , willing to give written informed consent and having good compliance with AEDs were selected. Patients with severe co-morbid diseases of the heart, lungs and other organ dysfunction, existing cognitive dysfunction were excluded from the study. Any side-effects reported by the patient or diagnosed by the physician were recorded in the standard ADR case reporting form.

\section{Parameters analyzed}

Quality of life

The QOLIE-10, an abbreviated questionnaire consisting of three domains and 10 questions about health and daily activities derived from QOLIE-31, has been used to assess the HR-QOL parameter". (Items scored with "1" as best were scored in Q1, Q4, Q5, Q6, Q7, Q8, Q10 and those with "1" as worst were scored in "reverse" in Q2, Q3, Q9. The total score is the sum of scores for all questions divided by the number of items answered. Thus, if a patient skipped an item, it is not reflected in the total score. Patients with lowest scores have the least problems.)

We have used the English and Gujarati version of the QOLIE-10.

\section{Statistical analysis}

Descriptive data has been expressed as mean $\pm \mathrm{SD}$, and percentages. The HR-QOLIE-10 scores have been expressed as mean $\pm \mathrm{SD}$ with $95 \%$ confidence intervals. Continuous variables have been analyzed using the unpaired $t$ test. Statistical significance was set at $\mathrm{p}<0.05$. Pearson correlation coefficient was applied to find out association between patient factors, prescription factors and HR-QOL.

\section{RESULTS}

\section{Demographic data}

A total of 127 patients were diagnosed with epilepsy by the treating neurologist with a male:female ratio of $1: 31$. The mean \pm SD for age was $33.5 \pm 15.17$ years for patients.

\section{Clinical characteristics and duration of disease}

Out of the total patients, 24 (18.9\%) had co-morbidities like hypertension (7.09\%), dyslipidaemia (6.30\%), hypothyroidism $(2.36 \%)$, diabetes mellitus $(0.79 \%)$, deep vein thrombosis $(0.79 \%)$, Parkinsonism $(1.57 \%)$. The mean \pm SD for duration of disease have been found to be $9.14 \pm 8.66$ years. $13(10.24 \%)$ of them had a positive family history of epilepsy and $17(13.39 \%)$ of them had addictions to nicotine, tobacco and cigarette.

\section{Previous episode and duration of seizure}

The mean $\pm \mathrm{SD}$ for previous seizure episode was $12.51 \pm 18.162$ months. Most of the episodes lasted for 110 minutes (94 74.02\%) approximately, with an overall spectrum from 2-3 seconds to an hour for a seizure episode (Table 1).

Table 1: Last seizure episode and average duration of seizures $(n=127)$.

\begin{tabular}{|lll|}
\hline Time since last seizure (months) & N & $\%$ \\
\hline $\mathbf{1}$ & 2 & 1.6 \\
\hline $\mathbf{2}$ & 8 & 6.3 \\
\hline $\mathbf{3}$ & 13 & 10.1 \\
\hline $\mathbf{4}$ & 24 & 18.9 \\
$\mathbf{5 - 1 0}$ & 39 & 31 \\
\hline $\mathbf{1 1 - 2 0}$ & 18 & 14 \\
\hline $\mathbf{2 0}$ & 23 & 18.1 \\
\hline
\end{tabular}




\section{Prescription pattern analysis}

Drug utilisation pattern is shown in the Table 2. All the drugs in $61.42 \%$ prescriptions were prescribed from the hospital formulary. The number of drugs prescribed by generic names was lesser than brand names. There were as low as $10(7.87 \%)$ prescriptions in which all the drugs were prescribed by their generic names whereas those having all drugs prescribed by the brand names was 35 $(27.56 \%)$.

Table 2: Drug utilization pattern.

\begin{tabular}{|ll|}
\hline Drug utilization pattern & Mean \pm SD \\
\hline $\begin{array}{l}\text { Average number of drugs prescribed } \\
\text { per encounter }\end{array}$ & $3.62 \pm 2.012$ \\
\hline $\begin{array}{l}\text { Average number of AEDs prescribed } \\
\text { per encounter }\end{array}$ & $2 \pm 1.069$ \\
\hline $\begin{array}{l}\text { Average cost per prescription for } \\
\text { AEDs }\end{array}$ & INR 276 \\
\hline
\end{tabular}

Out of the 462 AEDs prescribed, the most frequently prescribed was sodium valproate $(25.20 \%)$ (conventional) and levetiracetam (13.39\%) (newer). Optimal seizure control was also exerted by these drugs - patients receiving sodium valproate had the last seizure episode before 15 months and levetiracetam had the last episode before 13 months.

\section{Adverse drug reactions}

The major ADRs were found to be metabolic, manifested as weight disturbances.

\section{QOLIE-10 assessment}

The HR-QOL in the normal controls (Mean \pm SD: $2.02 \pm 0.06)$ was better than the patients (Mean \pm SD: $1.45 \pm 0.07)$.

Table 3: Mean and HR-QOL scores in each domain $(n=127)$.

\begin{tabular}{|lll|}
\multirow{2}{*}{ Domain } & Question number & $\begin{array}{l}\text { Mean } \pm \text { SD of } \\
\text { HR-QOL } \\
\text { scores in each } \\
\text { domain }\end{array}$ \\
\hline \multirow{4}{*}{$\begin{array}{l}\text { Epilepsy } \\
\text { effects }\end{array}$} & Q1) Energy levels & $3.65 \pm 2.184$ \\
\cline { 2 - 3 } & Q2) Downheartedness & $2.98 \pm 2.189$ \\
\hline \multirow{3}{*}{$\begin{array}{l}\text { Mental } \\
\text { effects }\end{array}$} & Q10) Overall HR-QOL & $2.34 \pm 1.311$ \\
\cline { 2 - 3 } & Q7) Physical effects & $2.12 \pm 1.445$ \\
\hline \multirow{4}{*}{$\begin{array}{l}\text { Role } \\
\text { function }\end{array}$} & Q8) Psychological & $1.83 \pm 1.334$ \\
& Qffects & $1.84 \pm 1.394$ \\
\cline { 2 - 3 } & Q3) Driving difficulties & $0.54 \pm 1.213$ \\
\cline { 2 - 3 } & Q5) Social limitations & $1.74 \pm 1.370$ \\
\cline { 2 - 3 } & $\begin{array}{l}\text { Q9) Fear of having } \\
\text { seizure }\end{array}$ & $1.86 \pm 1.252$ \\
\hline
\end{tabular}

The HR-QOLIE-10 questionnaire is divided into 3 domains such as (1) mental effects (2) epilepsy effects and (3) role function.

The scores in the epilepsy effects domain were the highest (worst HR-QOL), followed by mental effects. The role function domain was least affected (best HR-QOL). (Table 3).

\section{Comparison of HR-QOL in patients on monotherapy and polytherapy}

The mean and SD of HR-QOL scores in patients on monotherapy was $1.83 \pm 0.09$ (better HR-QOL) compared to those on polytherapy which was $2.13 \pm 0.08$ (Table 4 ).

Table 4: Comparison between HR-QOL in patients receiving monotherapy versus those on polytherapy $(n=127)$.

\begin{tabular}{|c|c|c|c|}
\hline $\begin{array}{l}\text { Score } \\
\text { range of } \\
\text { QOL }\end{array}$ & $\begin{array}{l}\% \text { patients on } \\
\text { monotherapy }\end{array}$ & $\begin{array}{l}\% \text { patients on } \\
\text { polytherapy }\end{array}$ & P value \\
\hline 0-1 & 4.17 & 1.27 & \multirow{5}{*}{$0.0226 *$} \\
\hline $1-2$ & 68.75 & 54.43 & \\
\hline $2-3$ & 20.83 & 34.17 & \\
\hline $3-4$ & 6.25 & 8.86 & \\
\hline $4-5$ & 0 & 1.27 & \\
\hline
\end{tabular}

Comparison of HR-QOL between patients on conventional and the newer drug therapy

The HR-QOL scores of patients on conventional drugs $(68.5 \%)($ Mean \pm SD: $1.96 \pm 0.07)$ are better than patients receiving the combined therapy with newer drugs (mean \pm SD: $2.15 \pm 0.12$ ) but it is not statistically significant as $\mathrm{p}$ value $>0.05$. Thus, there is no difference in the HRQOL among patients of the two groups (Table 5).

Table 5: Comparison of HR-QOL in patients receiving the conventional and combination of the conventional and newer drug therapies $(n=127)$

\begin{tabular}{|lll|l}
$\begin{array}{l}\text { QOL } \\
\text { score } \\
\text { range }\end{array}$ & $\begin{array}{l}\% \text { of patients } \\
\text { on } \\
\text { conventional } \\
\text { drug therapy }\end{array}$ & $\begin{array}{l}\text { \% of patients on } \\
\text { combination of } \\
\text { newer and } \\
\text { conventional } \\
\text { drug therapy }\end{array}$ & P value \\
\hline $\mathbf{0 - 1}$ & 3.44 & 0 & \\
\hline $\mathbf{1 - 2}$ & 60.92 & 57.5 & \multirow{2}{*}{0.1768} \\
\hline $\mathbf{2 - 3}$ & 28.74 & 30 & \\
\hline $\mathbf{3 - 4}$ & 6.90 & 10 & \\
\hline $\mathbf{4 - 5}$ & 0 & 2.5 & \\
\hline
\end{tabular}

\section{DISCUSSION}

Epilepsy is a chronic disease, its incidence being 0.2$0.6 \%$ per 1000 population and prevalence being 5.59 
persons per 1000 in India. ${ }^{10}$ This study is a sincere attempt by to evaluate drugs prescribed and HR-QOL in such patients which are expected to be affected.

\section{Socio-demographic characteristics}

Although the literature does not point to gender association with epilepsy, there was a slight male preponderance in our study, consistent with another study done by Mathur et al. ${ }^{11}$ But females might be prone to develop epilepsy at certain periods of menstrual cycle (catamenial epilepsy).

The patients in our study ranged from 18 to 76 years, majority falling in the younger adult age group of 18-30 years. This is in concordance with the study by Hasiso et al. ${ }^{12}$

In our study, about $60 \%$ of the patients diagnosed with epilepsy were productive to the society and employed in some capacity.

Hypertension and dyslipidaemia were the most common co-morbidities in our study. $10 \%$ of the patients had a positive family history of epilepsy. Various studies in Epileptic epidemiology among twins and the first-degree relatives of a patient with epilepsy of an idiopathic origin have proved the risk as $8-12 \%$ in such individuals as compared to the general population $(\sim 0.5 \%){ }^{13}$

In our study, majority of the patients had had a seizure in the last 2-24 months. As far as the last seizure episode went, $31 \%$ of the patients had the last seizure 5-10 months back. This infers that with drug therapy, the seizures can be controlled provided the patient is adherent to treatment. This finding in our study is crucial as it is a known fact that there is a patient subset which are called as suffering from refractory or treatment-resistant seizures and continue to have seizure frequently despite receiving multiple drugs for epilepsy.

\section{Prescription pattern analysis}

A total of 127 prescriptions were analyzed. The mean number of AEDs in our prescriptions was 2, which is quite similar to study by Mathur et al in which the average number of drugs was 1.56 .

A good feature that was observed in our study was that quite a lot of drugs were prescribed from the hospital formulary, giving the patients a relief from financial burden.

But on the flip side of the coin, significant number of drugs were seen to be prescribed by their brand names instead of their generic names. There were $7.87 \%$ of the prescriptions where all the drugs were prescribed by their generic names, which was low and can be improved.
Among all the AEDs, the least associated with a seizure occurrence in the recent past were sodium valproate, phenytoin, carbamazepine from the conventional class and among the newer drugs, levetiracetam, lacosamide and lamotrigine. Also, few AEDs that were not as efficacious were lorazepam, phenobarbital, topiramate, perampenal.

Sodium valproate among the conventional and levetiracetam among the new were the most frequently prescribed AEDs. Sodium valproate is an AED with wide therapeutic range and does not require frequent monitoring. So, it was the most used AED. This was contradicted by a study by Malerba et al in which the most commonly used AED in the conventional class was carbamazepine. ${ }^{14}$ Levetiracetam inhibits the $\mathrm{SV}_{2} \mathrm{~A}$ (synaptic vesicular protein) which modifies the synaptic release of glutamate and GABA through action on vesicular function. But in the same study by Malerba et al, the most commonly used AED in the newer class was found to be Levetiracetam which is consistent with our result. ${ }^{14}$

A total of 98 ADRs were reported by patients in the study. Most common system involved was central nervous system in the form of memory loss, headache, increased drowsiness which might have been due to the morbidity or the AEDs. A high number of ADRs of metabolic system were reported as weight gain $(27.56 \%)$ and weight loss $(9.45 \%)$. Most of the ADRs were explainable by the pharmacological action of the drug, predictable and did not warrant drug discontinuation. The weight gain is a common ADR seen with the use of sodium valproate and carbamazepine. The mechanism is not clear but increased blood levels of insulin due to insulin resistance by sodium valproate whereas with carbamazepine, the weight gain is attributed to increased fat deposition due to increased appetite. This can be one of the reasons of decreased compliance in the patients due to low confidence levels and may also worsen hypertension and diabetes mellitus. ${ }^{15}$

\section{Analysis of HR-QOL on patient receiving AEDs}

HR-QOL in patients of epilepsy was definitely affected negatively in comparison to controls, which was statistically significant.

Patients on more than one drug for epilepsy had a poor quality of life as compared to those taking a single AED. This difference was also statistically significant. A study by George et al also showed the same findings that patients on monotherapy had a significantly higher QOLIE score than did those on polytherapy $(\mathrm{p}=0.012)$, with no significant difference between patients on old and new AED. ${ }^{16}$ This fact can be explained, that patients receiving more than one drug have greater burden of the disease as well as they are likely to experience more side effects accounting for impairment in HR-QOL. 
The patients receiving conventional AED had lower scores in HR-QOL as compared to those receiving the combination therapy but that difference was not statistically significant $(\mathrm{p}>0.05)$. This finding shows that there is no difference in the HR-QOL among patients on conventional therapy or combination of conventional and newer therapies. The investigator found no study in the literature search which compared HR-QOL in these two groups. Although the initial intention of the study was to compare conventional and newer therapies, on data collection, prescriptions with only new drugs were very few (a total of 6 prescriptions only), hence it was decided to undertake comparison between conventional and combination of conventional and newer therapies .This also points to the prescribing behaviour, that physicians still put more reliance on conventional AED, despite the fact that some newer therapies including Levitaracetam, Lacosamide, Lamotrigine are establishing their role as monotherapy.

\section{Strengths of the study}

This study was the first such study carried out at our set up which evaluated the drug use pattern, HR-QOL. One advantage in our study was that we had an additional conclusive data about the patients on combinational therapy of conventional and the newer drugs. This study also provided insight into the commonly occurring side effects due to AEDs. An understanding of the degree of satisfaction of the lives of people with epilepsy will aid health-care providers to propose targeted interventions to improve their HR-QOL and health-care outcomes.

\section{Limitations of the study}

This was a cross-sectional single point study but if we had follow-ups, it would have yielded changes in HR-QOL reflected as success in drug therapy. We could have a comprehensive idea regarding the spectrum of side effects with these drugs. Univariate analysis of factors associated with the quality of life scores was not carried out i.e. comparing HR-QOL scores in relation to age, sex, employment status, educational background, marital status, last seizure episode was not performed. A Prospective study can now be planned to overcome these limitations.

\section{CONCLUSION}

We concluded that the HR-QOL was worse in patients of epilepsy as compared to normal controls. The patients on monotherapy had a better HR-QOL as compared to the patients on polytherapy. Patients on conventional therapy had a better HR-QOL as compared with those on combination therapy with newer drugs but that difference was not statistically significant.

\section{ACKNOWLEDGEMENTS}

Authors would like to acknowledge their esteemed dean, without whose motivation this project would not have shaped up, the institutional review board who gave suggestions for the betterment of the project and the neurology department. Author would like to acknowledge the willingness of the patients to participate in the study and help us come to a valuable conclusion.

Funding: Funding was obtained from the Indian Council of Medical Research

Conflict of interest: None declared

Ethical approval: The study was approved by the Institutional Ethics Committee

\section{REFERENCES}

1. Senthil A, Gopalkrishna G, Parthasarathy S. Epilepsy in India I: Epidemiology and public health. Annal Indian Acad Neurol. 2015;18(3):263-77.

2. Santulli L, Coppola A, Balestrini S, Striano S. The challenges of treating epilepsy with 25 antiepileptic drugs. Pharmacol Res. 2016;107:211-9.

3. Chung S, Ceja H, Gawlowicz J, McShea C, Schiemann J, Levetiracetam LS. Extended release for the treatment of patients with partial-onset seizures: a long-term, open-label follow-up study. Epilepsy Res. 2016;120:7-12.

4. Panebianco M, Zavanone C, Dupont S, Restivo D, Pavone A. Vagus nerve stimulation therapy in partial epilepsy: a review. Acta Neurol Belg. 2016;116(3)1-8.

5. French JA, Kanner AM, Bautista J, Abou-Khalil B, Browne T, Harden CL, et al. Therapeutics and technology assessment subcommittee of the American Academy of Neurology and the American Epilepsy Society. Neurology. 2004;62(8):1261-73.

6. Jacoby A. Epilepsy and the quality of everyday life: findings from a study of people with well-controlled epilepsy. Soc Sci Med. 1992;34:657-66.

7. Baker GA, Jacoby A, Buck D, Stalgis C, Monnet D. Quality of life of people with epilepsy: a European study. Epilepsia. 1997;38:353-62.

8. Thomas SV, Koshy S, Nair CR, Sarma SP. Frequent seizures and polytherapy can impair quality of life in persons with epilepsy. Neurol India. 2005;53:46-50.

9. Cramer JA, Perrine K, Devinsky O, Meader K. A brief questionnaire to screen for quality of life in epilepsy: the HR-QOLIE-10. Epilepsia. 1996;37:57782.

10. Amudhan S, Satishchandra P, Gururaj G. Epilepsy in India I: Epidemiology And Public Health. Annal Indian Acad Neurol. 2015;18(3):266-77.

11. Mathur S, Sen S, Ramesh L, Kumar S. Utilization pattern of antiepileptic drugs and their adverse effects, in a teaching hospital. Asian $\mathrm{J}$ Pharmaceut Clin Res. 2010;3(1):55-9.

12. Hasiso TY, Desse TA. Adherence to Treatment and Factors Affecting Adherence of Epileptic Patients at Yirgalem General Hospital, Southern Ethiopia: A Prospective Cross-Sectional Study. Plos One. 2016;11(9):e0163040. 
13. Poduri A, Lowenstein D. Epilepsy Genetics-Past, Present, and Future. Curr Opin Genet Dev. 2011;21(3):325-32.

14. Malerba A, Ciampa C, De Fazio S, Fattore C, Frassine B, La Neve A, et al. Patterns of prescription of antiepileptic drugs in patients with refractory epilepsy at tertiary referral centres in Italy. Epilepsy Res. 2010;91(2-3):273-82.

15. De Gaspari C, Guerreiro C. Modification in body weight associated with antiepileptic drugs. Arq Neuropsiquiatr. 2010;68(2):277-81.
16. George J, Kulkarni C, Sarma GRK. Antiepileptic Drugs and Quality of Life in Patients with Epilepsy: A Tertiary Care Hospital-Based Study. Value Health Reg Issues. 2015;6:1-6.

Cite this article as: Goswami KS, Rana DA, Shah S, Malhotra SD. Evaluation of differences in healthrelated quality of life in patients receiving conventional versus newer anti-epileptic drugs. Int $\mathbf{J}$ Basic Clin Pharmacol 2020;9:342-7. 